How Immigration May Affect U.S. Native Entrepreneurship: Theoretical Building Blocks and Preliminary Results

Harriet Orcutt Duleep

College of William and Mary and IZA

David Jaeger

City University of New York

Mark Regets

National Science Foundation and IZA

College of William and Mary

Department of Economics

Working Paper Number 134

March 2013 
COLLEGE OF WILLIAM AND MARY

DEPARTMENT OF ECONOMICS

WORKING PAPER \# 134

March 2013

\title{
How Immigration May Affect U.S. Native Entrepreneurship: Theoretical Building Blocks and Preliminary Results
}

\begin{abstract}
This paper describes the theoretical underpinnings and provides empirical evidence for a model that predicts a positive impact of immigration on entrepreneurial activity. Immigrants, we hypothesize, facilitate innovation and entrepreneurship by being willing and able to invest in new skills. At the heart of this theoretical prediction is the observation that human capital not immediately valued in the U.S. labor market is useful for learning new skills. Because immigrants face a lower opportunity cost of investing in new skills or methods, this "transfer" of source-specific skills to the U.S. may lead immigrants to be more flexible in their human capital investments than observationally equivalent natives. Areas with large numbers of immigrants (even if they are not self-employed) may prove to be areas in which entrepreneurship and innovation are easier to accomplish. Our theory offers a unique perspective on the contributions of immigrants to economic development beyond traditional perspectives that focus on low-cost immigrant labor or immigrant entrepreneurship.
\end{abstract}

JEL Codes: J15, J24, J39, J61, L26

Keywords: immigration, innovation, entrepreneurship, human capital investment, skill transferability, opportunity cost, learning transferability

Harriet Duleep (corresponding author)

Thomas Jefferson Program in Public Policy

College of William and Mary

Williamsburg VA 23187-8795

hduleep@wm.edu

David Jaeger

Program in Economics, Graduate Center of the City University of New York

365 Fifth Avenue,

New York, NY 10016

djaeger@gc.cuny.edu

Mark C. Regets

National Science Foundation

4201 Wilson Blvd., Room 965

Arlington, VA 22182

mregets@nsf.gov 


\title{
How Immigration May Affect U.S. Native Entrepreneurship: Theoretical Building Blocks and Preliminary Results
}

\author{
I. Introduction
}

With the movement away from the national-origin quota system in 1965, immigration to America increased substantially. Given differences in the relative economic opportunities between the United States and the countries whose immigration had been severely restricted prior to 1965 , the source-country composition of American immigration shifted from one of largely European origin to being predominantly from Asian and Latin American countries that are less economically developed than the United States. This sea change in the quantity and character of American immigration-like the waves of immigrants that arrived in the $19^{\text {th }}$ and $20^{\text {th }}$ centuries - has led to concerns about the impact of the new immigrants on the U.S. economy. A subject of intense debate among academics and policy makers is to what extent this large flow of foreigners has had a negative or positive impact on natives' labor market outcomes and the overall growth of the economy.

Other than two important and provocative studies of patent activity (Chellaraj, Maskus, and Mattoo, (2008) and Hunt and Gauthier-Loiselle, (2010)), an aspect of immigrants' impact in the U.S. that has received scant attention is the degree to which immigration affects innovation and entrepreneurial activity. Although it is well known that certain groups of immigrants are more likely to be self-employed than U.S. natives, 
little is known about how immigrants affect business development and the general ability of firms (including those owned and run by natives) to innovate. ${ }^{1}$

We postulate that immigration encourages new business formation by providing a flexible labor supply that is both willing and able to invest in new skills. This thesis departs from other explorations of entrepreneurship and immigration that focus on immigrants as entrepreneurs, often starting small family businesses. Part II introduces the theoretical building blocks of our immigration and entrepreneurship model, described in Part III. Part IV lays out the empirical model. Part V describes the data we use to test it. Part VI presents our results and discusses how our work relates to the study by Hunt and Gauthier-Loiselle.

II. Immigrants, Natives, and Human Capital Investment: Theoretical Foundations Chiswick $(1978,1979)$ theorized that migrants often lack skills specific to their destination country that would permit their home-country human capital to be fully valued in the host-country labor market. Immigrants initially earn less than similarly qualified U.S. natives because the specific skills and knowledge associated with their years of schooling and experience are not valued as much by U.S. employers as are the skills of individuals raised and schooled within the United States.

To increase the U.S. labor market value of their home-country human capital, immigrants engage in many forms of human capital investment such as learning English, pursuing various forms of informal and formal U.S. school and training, and becoming knowledgeable about U.S.-specific institutions, production methods, and technical terms.

\footnotetext{
${ }^{1}$ Another area that has received very little attention is whether and to what degree immigrant entrepreneurs may displace native-born entrepreneurs. See Fairlie and Meyer (2003) for an analysis of this issue. Our study looks at the potential effect of immigrants on natives' entrepreneurship via a labor supply effect.
} 
The specific "skills" needed to increase the U.S. labor market value of home-country human capital may also include credentials, such as a diploma or training certificate that is recognized by U.S. employers or is needed to perform a particular kind of work in the United States. As English and other U.S.-specific skills or credentials are gained, the value of the immigrant's home-country human capital approaches that of a comparably educated and experienced U.S. native.

Building on Chiswick's work, Duleep and Regets $(1999,2002)$ introduced an immigrant human capital investment (IHCI) model. This model starts with Chiswick's concept of international skill transferability, and then highlights two aspects of immigrant skill transferability. One, immigrants whose home-country skills do not fully transfer to the new labor market will, by virtue of their lower wages, have a lower opportunity cost of human-capital investment than natives: The time they spend learning new skills, instead of applying their current skills to earning, is less costly for them than it is for natives, who earn more with the same level of schooling and experience. Two, homecountry skills that are not fully valued in the host-country labor market are useful for learning new skills. Persons who have learned one set of skills — even if those skills are not valued in the destination-country labor market—have advantages in learning a new skill set: those with home-country skills have learned how to learn. Moreover, common elements between old and new skills aid learning. ${ }^{2}$

To clarify these points Duleep and Regets $(1999,2002)$ used a simple two-period model of human capital investment to describe the human capital investments of natives:

$$
\max _{\theta} \mathrm{w}_{1}(1-\theta)+\mathrm{w}\left(\mathrm{H}_{1}+\gamma f\left(\mathrm{H}_{1}, \theta\right)\right)
$$

\footnotetext{
${ }^{2}$ For more discussion on this point, refer to Duleep and Regets (1999, 2002).
} 
where $\mathrm{w}$ is the market rate of return on a unit of human capital, $\mathrm{H}_{1}$ is the initial stock of human capital, and $\theta$ is the proportion of available time devoted to investment in the first period. ${ }^{3}$ The optimal investment decision, $\theta^{*}$, maximizes total earnings over the two periods. The production function of human capital is denoted $\gamma f\left(\mathrm{H}_{1}, \theta\right)$ where $f$ is a positive function of $\theta$ and $\mathrm{H}_{1}$. The human capital production function is a function of $\gamma$, a human capital productivity coefficient that may vary across individuals.

Duleep and Regets note that even in this simple framework, the human capital investment decision of immigrants is more complicated and requires the introduction of two skill transferability parameters. An immigrant's initial stock of human capital, $\mathrm{H}_{1}$, was produced in their source country and may not be fully valued in their destination country. It is necessary to introduce a factor, $\tau_{\mathrm{M}}$, the proportion of source-country human capital that is initially valued in the labor market of the destination country. This skill transferability parameter could be referred to as "skill transferability to the labor market." It formalizes the discussion of international transferability of skills introduced by Chiswick $(1978,1979)$.

An immigrant's initial stock of human capital may also not fully transfer to the production of new, destination-country, human capital. To capture this feature, Duleep and Regets introduce a factor, $\tau_{\mathrm{P}}$, the proportion of source-country human capital that transfers to the production of new, destination-country human capital. The second skill

\footnotetext{
${ }^{3}$ While the proportion of time devoted to investment is a convenient concept of $\theta$ for exposition of the model, it could also be usefully thought of as the proportion of the U.S. market value of initial human capital that is foregone as a result of investment. This broader concept would include traditional forms of human capital investment such as apprenticeships or simply taking a job with lower initial pay, but greater opportunity for advancement.
} 
transferability parameter could be referred to as "skill transferability to human capital production."

For immigrants, the two-period model of human capital investment becomes:

$$
\max _{\theta} \mathrm{w} \tau_{\mathrm{M}} \mathrm{H}_{1}(1-\theta)+\mathrm{w}\left(\tau_{\mathrm{M}} \mathrm{H}_{1}+\gamma \tau_{\mathrm{P}} f\left(\mathrm{H}_{1}, \theta\right)\right)
$$

When $\tau_{M}<1$, the opportunity cost of investment for immigrants is lower than for natives with the same level of human capital in period 1. Yet, despite lower opportunity costs, there would not necessarily be a greater incentive for immigrants to invest in destination-country human capital than natives. If $\tau_{M}=\tau_{\mathrm{P}}$, the lower opportunity cost of investment resulting from low skill transferability to the labor market will be offset by higher human capital production costs.

Duleep and Regets argue, however, that when $\tau_{\mathrm{M}}<1$, it will generally be the case that the proportion of source-country human capital that transfers to the labor market will be less than the proportion of source-country human capital that transfers to the production of new human capital. Their reasoning follows.

It seems safe to assume that human capital that transfers to the labor market will also transfer to the learning of new skills. Thus $\tau_{\mathrm{P}}$ is at least as large as $\tau_{\mathrm{M}}$. But, human capital that does not transfer to the labor market is still useful for learning new skills. Thus when $\tau_{\mathrm{M}}<1, \tau_{\mathrm{M}}<\tau_{\mathrm{P}}$ : when immigrants' human capital does not fully transfer to the host-country labor market, imported human capital will be more effective in learning than in earning.

A lower opportunity cost of human capital investment combined with the usefulness of undervalued human capital for creating new human capital creates a greater incentive for immigrants to invest in human capital than natives with similar levels of 
education and experience. Since human capital investment fuels earnings growth, the

IHCI model predicts that immigrants will experience higher earnings growth than natives.

Among immigrants, there will be an inverse relationship between entry earnings and

earnings growth. Immigrants whose skills do not initially fully transfer to the U.S. will

have lower initial earnings but higher earnings growth than immigrants with similar

levels of schooling and experience, but more transferable skills.

Consistent with the IHCI model, studies that follow cohorts over time and do not

impose a relationship between entry earnings and earnings growth find an inverse

relationship between immigrant entry earnings and earnings growth, and higher earnings

growth for recent immigrants than natives (e.g., Duleep and Regets, 1997a, 2002). ${ }^{4}$

Duleep and Regets' free-form cohort-based results are confirmed by similar analyses that

follow individuals over time and are therefore unaffected by immigrant emigration (e.g.

Duleep and Regets, 1997b; Duleep and Dowhan, 2002; Akresh, 2007). ${ }^{5}$

The IHCI model is further buttressed by studies of immigrant human capital

investment. Recent immigrants appear to have a higher propensity to invest in human

capital and do so over a longer period than otherwise similar natives. Adult immigrants

\footnotetext{
${ }^{4}$ Duleep and Regets also include zero earners and the self-employed. In their 1992 IZA paper they note: "Consistent with standard professional practice in estimating Mincer earnings functions, immigrant regression models that pool entry cohorts from two or more censuses typically limit the sample to employed individuals, and exclude the self-employed. These sample limitations may create severe problems when following a "synthetic" cohort over time: individuals eligible for the sample in the first census through normal employment may be ineligible for the sample in the second census due to selfemployment; individuals without earnings during the first census, because of low employability or time spent in school, might be fully employed during the second, biasing the estimated earnings growth of immigrants downwards. This issue applies to any cohort followed between censuses. But it is particularly important here as immigrants have high occupational mobility, high in-school rates, and high rates of movement into self-employment. To avoid these difficulties we place no labor force status restrictions on our census cohorts."

${ }^{5}$ Duleep and Regets also find that immigrants with low initial skill transferability, as measured by admission criteria, have greater human capital investment, hence greater earnings growth, than immigrants with high initial skill transferability (e.g. Duleep and Regets, 1992, 1996a, 1996b). Also see Jasso and Rosenzweig (1995) on this point. For a synopsis of other evidence confirming the inverse relationship, refer to Duleep and Regets (1996c, 1999).
} 
are more likely to be enrolled in school and at older ages than natives (Duleep and Regets, 1992). A study of Canadian immigrants by Green (1999) reports higher rates of occupational change and at older ages for immigrants than for natives.

Another prediction from the IHCI model is that the difference in the propensity to invest between immigrants and natives will tend to be greatest for the highly educated.

In most human capital models, prior education has an ambiguous effect upon investment decisions: An increase in an individual's education increases both the opportunity cost of time spent in human capital investment and the productivity of that time. In the IHCI model, source-country human capital that is not valued in the destination-country labor market is useful for gaining new skills. Yet, because it is not valued in the host-country's labor market, it does not increase the opportunity cost of time spent in human capital investment. Consistent with these theoretical expectations, Duleep and Regets (2002) find that the earnings growth of the more educated versus the less educated is higher among immigrants coming from economically developing countries than it is for immigrants coming from economically developed countries.

In the original Chiswickian $(1978,1979)$ model, which introduced the idea of international skill transferability, immigrants initially earn less than natives because the skills they possess do not transfer completely to the U.S. labor market. As English and other U.S.-specific skills or credentials are gained, the value of the immigrant's homecountry human capital is restored. With its emphasis on the low opportunity cost of human capital investment for immigrants lacking transferable skills paired with the value of home-country human capital for learning new skills, a distinguishing feature of the Duleep/Regets IHCI model is its more general conclusion that the higher incentive to 
invest in human capital pertains not only to U.S.-specific human capital that restores the value of specific source-country human capital but to new human capital investment in general.

Thus, a potential benefit of immigrants — particularly highly educated immigrants - lacking immediately transferable skills is a high rate of human capital investment that is not tied to restoring specific home-country skills. When demand shifts requiring new skills to be learned, immigrants who initially lacked U.S.-specific skills will be more likely to pursue the new opportunities than will natives or immigrants with highly transferable skills. Recent immigrants may be better equipped than natives to dynamically respond to the changing skill needs of an economy (Green, 1999).

III. Immigrant Skill Transferability, the Propensity to Invest in Human Capital, and Entrepreneurship

Stepping through the looking glass and viewing the IHCI model from the employer's perspective suggests that a high propensity to invest in human capital, not tied to restoring the value of specific home-country skills by immigrants, may encourage entrepreneurship and innovation. ${ }^{6}$

To innovate is to introduce something new, such as a new method or product. In the U.S. market economy, entrepreneurship is a principal route through which innovations occur. But what facilitates entrepreneurship?

In deciding whether to develop a new product or service, potential entrepreneurs examine the costs and returns of pursuing such an activity. Returns are affected by the potential demand for a new product or service. In addition to capital outlays, a crucial

\footnotetext{
${ }^{6}$ The model form the employer's point of view was first introduced in Duleep (2008).
} 
cost of any new venture, particularly an innovative one, is training the workforce that will create the new product or service. New businesses require people who are willing and able to acquire new human capital. The extent to which this is true may be a function of how innovative the new business is. Indeed, one measure of innovativeness might be the distance between the skills needed to produce a new product or service and the existing set of skills: the greater the difference, the greater the innovation.

The cost of training employees to produce a new product or service is affected by the wage entrepreneurs have to pay employees while they are being trained and the return in terms of the value of the new human capital produced through the training. The wage entrepreneurs have to pay employees while they are being trained is determined by the opportunity cost of potential employees. That is, what can they get elsewhere?

For U.S. natives, the opportunity cost of training can be denoted as $w_{1} \theta$, where $w$ is the market rate of return on a unit of human capital, $H_{1}$ is the initial stock of human capital, and $\theta$ is the proportion of available time devoted to the training. The return to training can be expressed as w $\gamma f\left(H_{1}, \theta\right)$ where $\gamma f\left(H_{1}, \theta\right)$, the production of human capital, is a positive function of $\theta, H_{1}$, and of $\gamma$, a human capital productivity coefficient that may vary across individuals.

A key characteristic distinguishing immigrants from natives is skill transferability. Skill transferability affects the above formulation of training costs in two ways. The human capital acquired by immigrants in their countries of origin may not fully transfer to the U.S. labor market. To capture this feature, we introduce a factor, $\tau_{M}$, the proportion of source-country human capital initially valued in the labor market of the destination country. For immigrants, the opportunity cost of training can be denoted as: 
$w \tau_{M} H_{1} \theta$. When $\tau_{M}<1$, that is when immigrant skills are not fully valued in the U.S. labor market, the opportunity cost of training is lower for immigrants than for U.S. natives with the same level of human capital by $w H_{1}\left(1-\tau_{M}\right)$.

An immigrant's initial stock of human capital may also not fully transfer to the production of new, destination-country human capital. Language difficulties, differences in educational background, and lack of familiarity with U.S. technologies and work processes may lower an immigrant's ability to learn new U.S.-specific human capital relative to his or her U.S.-born counterpart with comparable levels of previous training and education. To capture this feature, we include a transferability factor $\tau_{P}$ in the production function for new human capital. The return to training for immigrants can then be expressed as $w \gamma \tau_{P} f\left(H_{1}, \theta\right)$.

If $\tau_{M}=\tau_{P}$, the advantage to immigration in terms of lower training costs, via their lower opportunity costs, would be offset by their lower returns to training. However, the reasoning presented in the IHCI model prevails: when skills are not fully transferable to the labor market, $1 \geq \tau_{P}>\tau_{M} \geq 0$. In comparing immigrants and natives with the same level of human capital, this model implies lower training costs for the immigrants.

Another prediction from the IHCI model is that the difference in the propensity to invest in human capital between immigrants and natives will likely be greatest for the highly educated. We would thus expect the immigration effect on entrepreneurship to be most consistently apparent for highly educated immigrants.

Finally, the above theory implies that the more innovative a particular venture is, the lower the training costs of immigrants relative to U.S. natives. We see this by returning to the notion of skill transferability. We stated that an immigrant's initial stock 
of human capital might not fully transfer to the production of new, destination-country, human capital. Yet, it also seems likely that the more innovative a product or service is, the greater the distance between the current set of available skills in the U.S. native labor force and the skills that would be needed for a new firm or industry. The more innovative it is, the less native-born skills would transfer to the new industry. The more innovative it is, the less the distance would be between $\tau_{P}$ for immigrants versus the U.S. born. At the same time, the opportunity cost of training for natives would be unaffected. This implies that the more innovative the venture, the more helpful the availability of immigrant labor would be.

\section{The Estimating Model}

From the above discussion several testable hypotheses emerge that inform the specification of our empirical model:

1. According to the Duleep/Regets' IHCI model, immigrants whose skills do not fully transfer to the U.S. have human capital that is undervalued in the U.S. labor market and yet useful for learning new skills. This translates into a higher propensity to invest in human capital—including human capital that is not tied to reviving the value of the immigrant's specific source-country human capital—hence a lower cost of training than observationally equivalent U.S. natives. We would therefore expect to find a positive effect of immigration on entrepreneurship.

2. Although it is well known that some groups of recent U.S. immigrants are more likely to be self-employed than U.S. natives, our model proposes that immigration's effect on business development and the ability of firms to innovate is via a labor supply 
effect. We would thus expect to find our anticipated immigration effect on the entrepreneurship and innovation of U.S. natives. This consideration suggests that in addition to testing for the effect of immigration on entrepreneurship in general, our empirical specification should separately test for the effect of immigration on U.S.native-only entrepreneurship.

3. For many immigrant groups, entrepreneurial ventures are characterized by small businesses in which the hires are paid and unpaid family members (e.g., Bates, 1996). Our model suggests that immigration affects entrepreneurship and innovation via a labor supply effect. We would therefore expect to more consistently find an immigration effect on natives' entrepreneurship than on immigrants' entrepreneurship. To compare the relative strength of the immigration effect on U.S.-born versus foreign-born entrepreneurship, our empirical specification should separately test for the effect of immigration on native-born versus foreign-born entrepreneurship.

4. In the Duleep/Regets IHCI model, the propensity to invest in human capital by immigrants tends to increase with education. Therefore, theoretically, we would expect the immigration effect on entrepreneurship to be most consistently apparent for highly educated immigrants. Our empirical specification should permit examining the effect of immigration on entrepreneurship by immigrants' level of schooling. Moreover, we would like our empirical specification to allow a comparison of the respective effects of highly educated immigrants versus highly educated natives on entrepreneurship.

5. Business startups typically experiment with a variety of new methods, products, and processes. We would thus expect that the effect of immigration on the creation of new establishments would be most relevant to the start-ups of new establishments by 
young firms versus new establishments in old firms. This suggests that our empirical specification should permit examining the effect of immigration on new establishment creation by the age of the firm.

\section{Causality}

In addition to the above issues that flow from the theoretical conceptualization underlying our model, there is a concern about causality: Does immigration affect entrepreneurship/innovation, or does entrepreneurship/innovation affect immigration? That is, if we find a positive effect of immigration on entrepreneurship, does it simply reflect a process wherein immigrants move to areas and industries that are entrepreneurial and innovative?

Instrumental variable (IV) estimation, typically used to deal with simultaneity, suffers from the imprecision inherent in using a proxy for the variable whose effect we wish to estimate. If the instrumental variable and the original variable are not highly correlated, then the estimated effect will be imprecise.

In this analysis, to control for omitted variables that could affect both immigration and entrepreneurship, we include time and state fixed effects as well as time and statespecific measures of unemployment. Perhaps more persuasively, however, we gauge the effect of immigration on entrepreneurship via the following thought experiment.

It seems reasonable to assume that the migration decisions of immigrants are no more affected by entrepreneurial activity than are U.S. natives of comparable schooling. In fact, research suggests that the migration decisions (where to locate in the U.S.) of immigrants are less affected by economic conditions than is true of U.S. natives, the 
reason being that immigrants' choices as to where to live are more affected by geographic concentrations of immigrants from the same source country.

Assuming that the migration decisions of immigrants and natives are equally affected by economic conditions, then - if the immigration effect on entrepreneurship were solely due to the reverse causal effect, we would not expect to see an immigrant effect that exceeded the comparable effect for natives. This is another reason why our empirical specification should permit a comparison of the respective effects of highly educated immigrants versus highly educated natives on entrepreneurship.

\section{Empirical specification}

Reflecting these considerations, the basic form of our empirical specification regarding the relationship between business development and immigrant concentrations is

$$
B D_{t j}=\alpha+\beta I_{t j}+\gamma U_{t j}+\lambda_{t}+\gamma_{j}+\varepsilon_{t j}
$$

where $j=1 \ldots n$ and $t=1 \ldots T, B D_{t j}$ is business development in time $t$ and area $j, I_{t j}$ is immigration share of workforce at time $t$ in area $j, U_{t j}$ is unemployment (as a measure of demand) in time $t$ and area $j, \lambda_{t}$ and $\gamma_{j}$ are time and area fixed effects, respectively.

In light of the theoretical analysis, we modified this basic empirical specification to include state and year-specific shares of immigrants and shares of natives by education level. Adding these shares to the model permits us to test how immigration's effect on entrepreneurial activity changes with immigrants' level of schooling. This formulation also lets us measure the effect on business formation and entrepreneurial activity of immigrants, by schooling level, relative to natives with similar levels of schooling. The 
shares by education groups included dropouts (low skill), high school grads/some college (medium skill), and college grads (high skill).

\section{The Data}

Data that measure business creation is key to the success of our endeavor. One approach would be to measure the creation of new businesses by differencing establishment counts over consecutive periods of time. A second measure of business formation would be to difference counts of the total number of individuals in non-farm self-employment from the Current Population Survey (CPS) and decennial Census data.

These measures are problematic because changes in the number of businesses or entrepreneurs reflect new businesses and business deaths. For instance, in the state- and time-specific statistics, an increase in the number of firms or entrepreneurs could be due to increased business creation or to fewer firms and entrepreneurs going out of business or to some combination of these processes.

We needed data on the initiation of new firms and the initiation of entrepreneurial activities. This requires data with either the age of the firm or some other indication of the initiation of a new business enterprise.

One source that we used is the Kaufman Index of Entrepreneurial Activity. This series measures month-to-month transitions to self-employment. Pioneered by Robert Fairlie, new business ventures are identified by identifying new entrepreneurs. Linking monthly Current Population Survey (CPS) files, one can follow individuals. New entrepreneurs are identified by identifying in the first file of any year persons who do not own a business as their main job (defined as 15 or more hours worked in general per 
week) and then determining whether these individuals own a business as their main job in the following survey month. Using this methodology, series of the annual average of month-to-month transitions to self-employment, stratified by state, immigrant status, and industry were created and are available on the Kaufman Foundation website.

The other data source we used is the Business Dynamics Statistics series.

The Census Bureau maintains a business registrar with annual historical data; its records include when each establishment started. The Longitudinal Business Database links together the files from the Business Registrar and other relevant data (e.g., the economic census) to form longitudinal data on establishments. The Longitudinal Business Database contains the start date of any given establishment, the industry it is in, and the state the establishment is in, all in establishment-level format.

The Census Bureau recently created the Business Dynamics Statistics series, based on the Longitudinal Business Database, to meet the demands of researchers who ask for tabulations from the Longitudinal Business Database. The Business Dynamics Statistics series is public use (aggregated) data, with time series of new establishments, by year, state, and industry.

With these data, we created time-series-cross-sectional data that matches at a state level and industry level the new entrepreneur data and the Business Dynamics Statistics on firm creation, establishment creation, and job creation to annual March Current Population Survey data on immigrant and native shares of the labor force by education level and annual/state unemployment rates. 


\section{Discussion of Results}

The empirical model utilizes regression analysis to assess how immigration affects business formation across states and industries over time, controlling for other relevant factors that may affect business growth. The following empirical analyses were conducted:

1. Analyses of the effect of immigration on entrepreneurship by state and by industry using the annual average month-to-month transition to self-employment as the measure of entrepreneurship.

2. Analyses of the effect of immigration on firm creation by state and by industry using the Business Dynamics Statistics data.

A synopsis of our results follows:

\section{Analysis with the Kaufman Index of Entrepreneurial Activity}

We hypothesized that the presence of well-educated immigrants in the work force would facilitate entrepreneurship, and that the effect of highly-educated immigrants would exceed that of highly educated natives. As shown in Table 1, states with higher shares of college-educated immigrants in their work force have higher rates of new entrepreneurship. Moreover, the per capita effect of college-educated immigrants on new entrepreneurship is nearly double-1.8 times - the effect of college-educated natives on new entrepreneurship.

As shown in Table 4, industries with higher shares of college-educated immigrants in their work force have higher rates of new entrepreneurship. And the effect 
of college-educated immigrants on new entrepreneurship by industry is more than 7 times the effect of college-educated natives on new entrepreneurship.

\section{New Entrepreneurship by U.S. Natives}

As shown in Table 2, states with higher shares of college-educated immigrants in their work force have higher rates of new entrepreneurship by U.S. natives. The effect of college-educated immigrants on new entrepreneurship by U.S. natives is about 1.7 times the effect of college-educated natives on new entrepreneurship by U.S. natives.

As shown in Table 5, industries with higher shares of college-educated immigrants in their work force have higher rates of new entrepreneurship by U.S. natives. The effect of college-educated immigrants on new entrepreneurship by U.S. natives is about 18 times the effect of college-educated natives on new entrepreneurship by U.S. natives.

\section{Analysis with the Business Dynamics Statistics data}

As shown in Table 8, states with higher shares of college-educated immigrants in their work force have higher rates of new establishment creation by young firms. The effect of college-educated immigrants on new establishment creation by young firms far exceeds the corresponding effect of college-educated natives.

\section{Other Confirmatory Evidence: The Patent Study by Hunt and Gauthier-Loiselle}

The results in the Hunt/Gauthier-Loiselle paper support our theory. In particular, they find that there is an immigrant effect on innovation beyond what can be explained by 
immigrant's own propensity to innovate, as measured by patent activity. Moreover, they find that the immigrant effect on the spill-over effect is greatest for highly educated immigrants - a finding also predicted by the immigration-innovation model.

The evidence for a spill-over effect in the Hunt/Gauthier-Loiselle paper is indirect. Based on their study of patent activity by immigrants, given in the first part of their paper, they predict patent activity by U.S. area. The activity beyond what is predicted is evidence of a spill-over native effect. Hunt/Gauthier-Loiselle suggest that the immigration effect on patent activity, beyond that which can be explained by immigrant innovators, stems from having a critical mass of innovators in any given place and time.

$* * *$

In summary, our results consistently suggest that college-educated immigrants lead to increased innovation in a variety of dimensions that includes entrepreneurship, establishment entry, and job creation. Greater shares of college-educated natives also lead to increased entrepreneurial activity. However, the per capita effect on entrepreneurial activity of immigrants far exceeds that of natives.

Although it is well known that some groups of immigrants are more likely to be self-employed than natives, little is known about how immigrants affect business development in general. A distinguishing feature of our model is that the availability of immigrant labor—given its high propensity to invest in human capital—fosters innovation and business development. That higher shares of college-educated immigrants lead to increased entrepreneurial activity of natives suggests that benefits of immigrants are greater than just their direct innovative activity. 
Table 1

Effect of Immigrant Shares of 20-64 Year Old Labor Force on

Entrepreneurship (All Entepreneurs) by State

2003-2008

Total Immigrant Share $\quad 0.00254$

(0.00475)

High Skill Immigrant Share

$\begin{array}{lccc}0.01579 & 0.01694 & 0.02269 & 0.02753 \\ (0.00936) & (0.00934) & (0.01070) & (0.01076)\end{array}$

(0.00936)

$(0.00934)(0.01070)(0.01076)$

High Skill Native Share

$\begin{array}{cccc}0.00571 & 0.00616 & 0.01278 & 0.01533 \\ (0.00352) & (0.00351) & (0.00655) & (0.00656)\end{array}$

Medium Skill Immigrant Share

$\begin{array}{ll}0.00254 & 0.00509\end{array}$

(0.00948) (0.00943)

Medium Skill Native Share

$0.00723 \quad 0.00884$

(0.00607) (0.00604)

Low Skill Immigrant Share

$0.01115 \quad 0.01098$

(0.01021) (0.01010)

Unemployment Rate

0.01781

(0.00718)

\begin{tabular}{lcccccc} 
State Fixed Effects & $X$ & $X$ & $X$ & $X$ & $X$ & $X$ \\
Year Fixed Effects & $X$ & $X$ & $X$ & $X$ & $X$ & $X$ \\
$N$ & 294 & 294 & 294 & 294 & 294 & 294 \\
\hline
\end{tabular}

Source: Author tabulations from CPS data.

Entrepreneurial index courtesy of Kaufmann Foundation and Rob Fairlie. Immigrant shares tabulated from March IPUMS-CPS data. 
Table 2

Effect of Immigrant Shares of 20-64 Year Old Labor Force on

Entrepreneurship (Natives) by State

2003-2008

Total Immigrant Share

0.00387

(0.00459)

High Skill Immigrant Share

$\begin{array}{cccc}0.01210 & 0.01284 & 0.01948 & 0.02355 \\ (0.00906) & (0.00908) & (0.01038) & (0.01048)\end{array}$

High Skill Native Share

$\begin{array}{llll}0.00363 & 0.00396 & 0.01170 & 0.01384\end{array}$

$\begin{array}{llll}(0.00341) & (0.00341) & (0.00636) & (0.00639)\end{array}$

Medium Skill Immigrant Share

$0.00521 \quad 0.00736$

(0.00920) (0.00918)

Medium Skill Native Share

$0.00809 \quad 0.00945$

(0.00589) (0.00588)

Low Skill Immigrant Share

$0.01441 \quad 0.01426$

(0.00990) (0.00983)

Unemployment Rate

0.01497

(0.00699)

State Fixed Effects

Year Fixed Effects

\section{$X$}

N

294

$\mathrm{X}$

$X$

$\mathrm{X}$

$X$

$294 \quad 294 \quad 294$

\begin{tabular}{cc}
$X$ & $X$ \\
$X$ & $X$ \\
294 & 294 \\
\hline
\end{tabular}

Source: Author tabulations from CPS data.

Entrepreneurial index courtesy of Kaufmann Foundation and Rob Fairlie. Immigrant shares tabulated from March IPUMS-CPS data. 
Table 3

Effect of Immigrant Shares of 20-64 Year Old Labor Force on

Entrepreneurship (Immigrants) by State

2003-2008

Total Immigrant Share

High Skill Immigrant Share

High Skill Native Share

Medium Skill Immigrant Share

Medium Skill Native Share

Low Skill Immigrant Share

Unemployment Rate

0.00389

(0.02374)

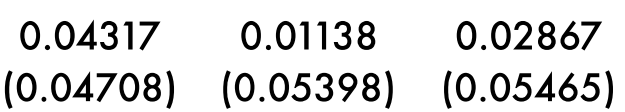

$\begin{array}{llll}0.01408 & 0.01522 & -0.01733 & -0.00822\end{array}$

$\begin{array}{llll}(0.01763) & (0.01768) & (0.03306) & (0.03333)\end{array}$

$\begin{array}{cc}-0.04454 & -0.03541 \\ (0.04781) & (0.04789)\end{array}$

$\begin{array}{ll}-0.03581-0.03006 \\ -0.03060) & (0.03065)\end{array}$

(0.03060) (0.03065)

$\begin{array}{ll}-0.01776 & -0.01839\end{array}$

(0.05148) (0.05126)

0.06360

(0.03644)

\begin{tabular}{lcccccc} 
State Fixed Effects & $X$ & $X$ & $X$ & $X$ & $X$ & $X$ \\
Year Fixed Effects & $X$ & $X$ & $X$ & $X$ & $X$ & $X$ \\
$N$ & 294 & 294 & 294 & 294 & 294 & 294 \\
\hline
\end{tabular}

Source: Author tabulations from CPS data.

Entrepreneurial index courtesy of Kaufmann Foundation and Rob Fairlie. Immigrant shares tabulated from March IPUMS-CPS data. 
Total Immigrant Share

\subsection{0}

$(0.00225)$

High Skill Immigrant Share

$\begin{array}{cccc}0.00792 & & 0.00603 & 0.01497 \\ (0.00419) & & (0.00421) & (0.00497) \\ & & & \\ & -0.00638 & -0.00604 & 0.00229 \\ & (0.00176) & (0.00177) & (0.00315)\end{array}$

Medium Skill Immigrant Share

0.00157

$(0.00434)$

Medium Skill Native Share

0.00863

(0.00272)

Low Skill Immigrant Share

0.01776

(0.00426)

Unemployment Rate

$\begin{array}{lccccc}\text { State Fixed Effects } & X & X & X & X & X \\ \text { Year Fixed Effects } & X & X & X & X & X \\ N & 1578 & 1578 & 1578 & 1578 & 1578\end{array}$

Source: Author tabulations from CPS data. Entrepreneurial index courtesy of Kaufmann Foundation and Rob Fairlie. Immigrant shares tabulated from March IPUMS-CPS data. 
Table 5

Effect of Immigrant Shares of 20-64 Year Old Labor Force on

Entrepreneurship (Natives) by Industry

2003-2008

$\begin{array}{ll}\text { Total Immigrant Share } & 0.00789 \\ (0.00251)\end{array}$

High Skill Immigrant Share

0.01048
$(0.00469)$

0.00833

0.01769

High Skill Immigrant Share

(0.00471)

(0.00555)

High Skill Native Share

$\begin{array}{lll}-0.00733 & -0.00687 & 0.00106 \\ (0.00197) & (0.00199) & (0.00352)\end{array}$

Medium Skill Immigrant Share

0.00195

(0.00485)

Medium Skill Native Share

0.00791

(0.00304)

Low Skill Immigrant Share

0.02315

Unemployment Rate

\begin{tabular}{|c|c|c|c|c|c|}
\hline State Fixed Effects & $\mathbf{X}$ & $\mathbf{X}$ & $\mathbf{X}$ & $\mathbf{X}$ & $\mathbf{X}$ \\
\hline Year Fixed Effects & $\mathbf{X}$ & $\mathbf{X}$ & $\mathbf{X}$ & $\mathbf{X}$ & $\mathbf{X}$ \\
\hline $\mathbf{N}$ & 1578 & 1578 & 1578 & 1578 & 1578 \\
\hline
\end{tabular}

Source: Author tabulations from CPS data. Entrepreneurial index courtesy of Kaufmann Foundation and Rob Fairlie. Immigrant shares tabulated from March IPUMS-CPS data. 
Effect of Immigrant Shares of 20-64 Year Old Labor Force on

Entrepreneurship (Immigrants) by Industry

2003-2008

Total Immigrant Share

\section{$-0.00634$}

(0.00895)

High Skill Immigrant Share

High Skill Native Share

Medium Skill Immigrant Share

Medium Skill Native Share

Low Skill Immigrant Share
$-0.00243-0.00076$

$(0.01687)(0.02012)$

(0.01673)

$\begin{array}{lll}-0.00011 & -0.00024 & 0.00248\end{array}$

$(0.00741)(0.00747) \quad(0.01290)$

$-0.01056$

(0.01753)

0.00369

(0.01110)

0.00246

(0.01722)

Unemployment Rate

\section{State Fixed Effects}

Year Fixed Effects

N

$\mathrm{X}$

1578

$\mathrm{X}$
$\mathrm{X}$

1578

$X$
$X$
1578

1578

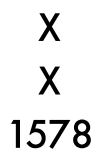

Source: Author tabulations from CPS data. Entrepreneurial index courtesy of Kaufmann Foundation and Rob Fairlie. Immigrant shares tabulated from March IPUMS-CPS data. 
Total Immigrant Share

$$
\begin{gathered}
0.05060 \\
(0.04925)
\end{gathered}
$$

High Skill Immigrant Share

$$
\begin{gathered}
0.12358 \\
(0.11776)
\end{gathered}
$$

High Skill Native Share

Medium Skill Immigrant Share

Medium Skill Native Share

Low Skill Immigrant Share

Unemployment Rate

State Fixed Effects

Year Fixed Effects

N

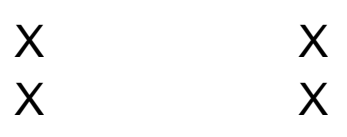

612

612

\section{$-0.00098$}

(0.03904)

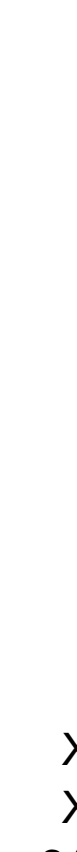

$\begin{array}{ccc}0.12372 & 0.16314 & 0.17313 \\ (0.11790) & (0.13723) & (0.13737)\end{array}$

$\begin{array}{lll}-0.01178 & 0.03956 & 0.04425\end{array}$

$\begin{array}{lll}(0.00859) & (0.06817) \quad(0.06823)\end{array}$

$\begin{array}{cc}0.06494 & 0.01490 \\ (0.11214) & (0.11212)\end{array}$

$0.04595 \quad 0.04950$

$(0.06729) \quad(0.06731)$

\section{$0.08948 \quad 0.07291$ \\ $(0.12217) \quad(0.12279)$}

0.09983

(0.07835)
$X$

$\mathrm{X}$

612 $x$

$X$

612
$X$

$\begin{array}{ll}x & X \\ X & X\end{array}$

$612 \quad 612$

Source: Author tabulations from CPS and Business Dynamics data. 
Table 8

Effect of Immigrant Shares of 20-64 Year Old Labor Force on

Entry of New Establishments Share of Total Number of Establishments (Young Firms)

1994-2005

Total Immigrant Share

0.00453

$(0.01098)$

High Skill Immigrant Share

0.08915

$(0.02589)$

High Skill Native Share

Medium Skill Immigrant Share

Medium Skill Native Share

Low Skill Immigrant Share

Unemployment Rate

State Fixed Effects

Year Fixed Effects

$N$

$\begin{array}{cc}X & X \\ X & X \\ 612 & 612\end{array}$

0.09016

$(0.02588)$

0.07944

0.07138

$-0.01092$

$$
(0.00868)
$$

$-0.01178$

$(0.00859)$

$-0.01808$

$(0.01479)$

$-0.02189$

$(0.01469)$

$$
\begin{array}{cc}
0.01770 & 0.01490 \\
(0.02414) & (0.02393)
\end{array}
$$

$-0.00641 \quad-0.00919$

$(0.01452) \quad(0.01440)$

$-0.08312-0.07582$

$(0.02626) \quad(0.02611)$

$-0.05597$

(0.01700)

Source: Author tabulations from CPS and Business Dynamics data. 


\section{References}

Akresh, I.R. (2007) “U.S. Immigrants' Labor Market Adjustment: Additional Human Capital Investment and Earnings Growth.” Demography, 44(4): 865-881.

Bates, Timothy, (1996) "Determinants of Survival and Profitability Among Asian Immigrant-Owned Small Businesses," in H. Duleep and P. V. Wunnava (editors), Immigrants and Immigration Policy: Individual Skills, Family Ties, and Group Identities, Greenwich, CT: JAI Press, pp. 150-176.

Chellaraj, Gnanaraj, Keith Maskus, and Aaditya Mattoo, A. (2008), "The Contribution of International Graduate Students to US Innovation," Review of International Economics, 16: 444-462

Chiswick, Barry R. (1978) "The Effect of Americanization on the Earnings of Foreignborn Men," Journal of Political Economy 86(5):897-921.

—, (1979) "The Economic Progress of Immigrants: Some Apparently Universal

Patterns," in Contemporary Economic Problems, William Fellner, ed.

Washington, D.C.: American Enterprise Institute, 357-399.

Duleep, Harriet (2008) "Immigrant Skill Transferability and the Propensity to Invest in Human Capital," in Immigration: Trends, Consequences and Prospects for the United States, ed. Barry R. Chiswick, IZA, Elsevier, JAI, pp. 43-73.

Duleep, Harriet and Daniel J. Dowhan (2002) "Insights from Longitudinal Data on the Earnings Growth of U.S. Foreign-born Men,” Demography, August.

Duleep, Harriet Orcutt and Mark Regets (1992) "Some Evidence on the Effect of Admission Criteria on Immigrant Assimilation," in Immigration, Language and Ethnic Issues: Canada and the United States, Barry Chiswick (ed.). Washington, D.C.: American Enterprise Institute, pp. 410-439.

—, (1996a) "Family Unification, Siblings, and Skills," in Harriet Duleep and Phanindra Wunnava (eds.), Immigrants and Immigration Policy: Individual Skills, Family Ties, and Group Identities, Greenwich, CT: JAI Press.

—, (1996b) "Admission Criteria and Immigrant Earnings Profiles," International Migration Review, Summer.

—, (1996c) "Earnings Convergence: Does it Matter Where Immigrants Come From or Why?" Canadian Journal of Economics, vol. 29, April 1996, pp. S130-S134

—, (1997a) "The Decline in Immigrant Entry Earnings: Less Transferable Skills or Lower Ability?" Quarterly Review of Economics and Finance, 37, Special Issue on Immigration, pp. 189-208.

—, (1997b) "Measuring Immigrant Wage Growth Using Matched CPS Files." Demography 34 (2) May, pp. 239-249.

-, (1997c) "Immigrant Entry Earnings and Human Capital Growth," Research in Labor Economics, vol. 16, 297-317.

—, (1999) "Immigrants and Human Capital Investment," American Economic Review, May, pp. 186-191.

—, (2002 )"The Elusive Concept of Immigrant Quality: Evidence from 1970-1990," IZA Discussion Paper, no. 631. 
Fairlie, Robert W. and Bruce D. Meyer (1998) "Does Immigration Hurt AfricanAmerican Self-Employment? " in Help or Hindrance? The Economic Implications of Immigration for African-Americans, Daniel S. Hamermesh and Frank D. Bean, eds. New York: Russell Sage Foundation.

—, (2003) "The Effect of Immigration on Native Self-Employment," Journal of Labor Economics. 21(3): 619-650.

Fairlie, Robert W. and Christopher Woodruff (2006) "Mexican Entrepreneurship: A Comparison of Self-Employment in Mexico and the United States" in Mexican Immigration, George Borjas, ed. Cambridge: NBER.

Green, David A. (1999) "Immigrant Occupational Attainment: Assimilation and Mobility over Time," Journal of Labor Economics 17(1): 49-79.

Hunt, Jennifer and Marjolaine Gauthier-Loiselle, (2010) "How Much Does Immigration Boost Innovation?" American Economic Journal: Macroeconomics

Jaeger, David A. (2007) "Green Cards and the Location Choice of Immigrants in the United States, 1971-2000," Research in Labor Economics,.

Jasso, Guillermina and Mark R. Rosenzweig, (1995) "Do Immigrants Screened for Skills Do Better than Family-Reunification Immigrants?," International Migration Review 29(1):85-111. 